\title{
Choice, Habit and Evolution
}

\author{
Geoffrey M. Hodgson
}

20 October 2008

To be published in the Journal of Evolutionary Economics

\begin{abstract}
The Business School, University of Hertfordshire, De Havilland Campus, Hatfield, Hertfordshire AL10 9AB, UK www.geoffrey-hodgson.info g.m.hodgson@herts.ac.uk
\end{abstract}

\begin{abstract}
Several leading mainstream economists including Gary Becker have treated habit as serially correlated behaviour resulting from deliberate choices. This approach puts choice before habit but involves assumptions of extensive memory and decision-making capacity. By contrast, earlier authors such as William James, John Dewey and Thorstein Veblen saw deliberation and choice as a contingent outcome of habits, where the latter are defined in terms of acquired dispositions rather than overt behaviour. The approach of this second group is more consistent with an evolutionary perspective and the limited computational capacities of the human brain.
\end{abstract}

In some way or another, it is widely accepted that habits affect our choices, and past choices affect habits. ${ }^{1}$ Beyond this consensus, however, there is dispute whether habit or choice are ultimately in the driving seat. For most economists, decision and choice have been uppermost and habit has followed in its wake. After all, economics since Lionel Robbins (1932) has been dubbed 'the science of choice'.

\footnotetext{
1 The author is grateful to an anonymous referee and participants at an Erfurt workshop on 'Automaticity in Judgement and Decision Making', 28 February - 1 March 2008, for comments on earlier drafts of this paper.
} 
Choice is made supreme even in the works of economists who apparently embrace a concept of habit. Notably Gary Becker (1992) assumes a meta-preference function which is revealed to the agent through experience, and is apparently consistent with behavioural 'habits' and 'addictions' (Becker and Murphy 1988). The (meta-) preference function supposedly a representation of the mechanism of choice - remains sovereign, and the claimed achievement is to accommodate even addictions or habitual behaviour in a rational choice model. ${ }^{2}$

The purpose of this paper is to challenge the idea that choice and decision have universal and ultimate sway over habit. It is argued by contrast that the prioritisation of choice faces the same problem of causal explanation of the origin of choice itself, both in the evolution of the human species and the development of a single individual. Sometimes economists seem like ungodly creationists who locate the unexplained origin of the capacity for choice in the individual, rather than God. As conventional creationists fail to explain the origins of God, conventional economists provide no evolutionary explanation of the origin of individual choice.

The corrosive effect of Darwinism on notions of supreme choice or deliberation was recognised by Darwin himself. Darwin wrote in 1856 in his notebooks: "Men are called "creatures of reason," more appropriately they would be "creatures of habit" (Darwin 1974, pp. 84, 115). The implications of Darwin's argument were developed by the psychologist and philosopher William James, and both in turn influenced John Dewey and Thorstein Veblen. Dewey (1894, pp. 338-9) responded to the proposition of an uncaused ego with the insistence that 'it becomes necessary to find a cause for this preference of one alternative over the other.' The causes of the causing ego have also to be explained.

Taking up this scientific imperative of universal causal explanation, this essay upholds that reason, deliberation and choice have evolved in humans on a bedrock of habits and instincts, which in turn have a much longer evolutionary history. Furthermore, for each individual, the capacity for deliberation and choice depends on habits and instincts, inherited respectively through our culture and our biology. Moreover, there is evidence that acts of deliberation are preceded by unconscious brain processes; these signify that our minds are disposed towards the choice outcome before we are aware of our decision, and show that conscious deliberation does not have temporal priority over associated, unconscious mental dispositions.

The consequences of this (essentially Darwinian) line of argument were well understood by James, Dewey, Veblen and others over one hundred years ago. But they were neglected in the social sciences from the 1920s until the 1990s. With the revival of a Darwinian impetus in the social sciences and psychology, they are enjoying a renewed appreciation by philosophers and social theorists today.

Before establishing its key propositions concerning the evolutionary and developmental prioritisation of instinct, habit, deliberation and choice, this paper discusses the nature and roles of habits and instincts, and how they relate to one another. After its core argument is completed, I consider some of the implications for economics and the social sciences.

\footnotetext{
2 In contrast, in a early paper Becker (1962) regarded rationality and habit as rival but similarly competent explanations of economic phenomena: habit was not explained in terms of rationality. After his meta-preference function appeared in later writings its intended ontological status remained unclear. Becker might follow Milton Friedman (1953) in proposing that the only scientific test of such a function is whether it makes 'correct predictions'. This leaves unanswered the vital question of what viable neural and psychological mechanisms actually underlie preferences or choice.
} 


\section{What are instincts?}

Purged from the Anglophone social sciences in the interwar years, the concept of instinct has now returned (Degler, 1991). Of course, many important details remain controversial, even beyond the familiar question of the relative importance of nature and nurture. But much of this can be avoided if we use the term broadly to describe any biologically inherited reflex, feeling or disposition that can be triggered by specific cues. Instincts are not fixed behaviours; they are dispositions that can often be suppressed or diverted. It is fully acknowledged that the expressions of these feelings or dispositions depend on the social context, including culture. Crucially, these dispositions can be diminished or suppressed by cultural and other conditions.

There is clear evidence for some human instincts. There are instinctive reflexes to clutch, suckle, and much else. In particular, after Noam Chomsky (1959) doubted the behaviourist view that language could develop simply through stimulus and response, it has been conclusively demonstrated that language cannot be learned simply through interaction with the environment. Newborn babies inherit the means of recognition and imitation of some vocal sounds, as well as some elemental understanding of linguistic structure (Pinker, 1994). Although the development of language is impossible without extensive social interaction, it is also impossible without priming instincts.

Instincts are aroused by circumstances and specific sensory inputs. Particular circumstances can trigger inherited instincts such as fear, imitation or sexual arousal. It is beyond the point to argue that acquired habit or socialization are much more important than instinct. Many of our dispositions and much of our personality are formed after birth. But the importance of socialization does not deny the necessary role of instinct. Both instinct and habit are vital for individual development. Inherited dispositions are necessary for socialization to begin its work. Obversely, much instinct cannot manifest itself without the help of culture and socialization. Instinctive behaviour and socialization are not always rivals but often complements: they interact with one another. The degree to which we are affected by our social circumstances is immense, but that is no ground for the banishment of the concept of instinct from social theory.

Some social scientists declare that instincts cannot by definition be overridden. They then produce evidence that claimed instincts can be diverted or blocked by culture, and then conclude that instincts are irrelevant for the social sciences (e.g. Robertson 1978). The flaw in this argument lies in its definitional premise. Instincts require contextual triggers to become operative, and they can be diverted or blocked. We understand human behaviour party through the interplay of (inherited) instincts and (acquired) habits. Instincts alone cannot explain outcomes.

\section{Definitions of Habit}

Unlike instinct, a habit is a propensity that is moulded by environmental circumstances and transmitted culturally rather than biologically. For James, Veblen and Dewey, habit was a propensity or disposition. It did not mean behaviour as such. James (1893, p. 143) proclaimed: 'Habit is thus the enormous fly-wheel of society, its most precious conservative agent.' Veblen (1898, p. 390) wrote of 'a coherent structure of propensities and habits which seeks realisation and expression in an unfolding activity'. As John Dewey (1922, p. 42) put it: 'The essence of habit is an acquired predisposition to ways or modes of response.'

The mechanisms of habit are largely unconscious, but they may press on our awareness. Habits are submerged repertoires of potential behaviour; they can be triggered or reinforced 
by an appropriate stimulus or context. The meaning of habit adopted by the pragmatist philosophers and instinct psychologists was of an acquired proclivity or capacity, which may or may not be actually expressed in current behaviour. A similar interpretation of habit as a disposition is found in the work of contemporary psychologists (Ouellette and Wood 1998, Wood et al. 2002, Wood and Neal 2007).

Brain imaging studies on human subjects (Poldrack et al., 2001) show that the formation of habits involves a shift away from parts of the brain associated with conscious, declarative memory and goal-setting (the medial temporal lobe and pre-frontal cortex) towards areas associated with procedural memory and context-triggered responses (the basal ganglia).

Repeated behaviour is important in establishing a habit. But if we acquire a habit we do not necessarily use it all the time. It is a propensity to behave in a particular way in a particular class of situations.

This conception of habit contrasts with that used by some other authors. For example, Gary Becker (1992, p. 328) wrote: 'I define habitual behavior as displaying a positive relation between past and current consumption'. Becker here defines habit not as a behavioural propensity but as sequentially correlated behaviour. In contrast, the view of habit here is of a disposition, which, once acquired, is not necessarily realised in any future behaviour. Habit is a causal mechanism, not a set of correlated events.

\section{Habit and scarce computational capacity}

Becker's behaviourist (non-dispositional) definition of habit allows him to argue that habit (as behaviour) is always based upon and derived from rational choice. By contrast, a habit (as a disposition) cannot be so readily and universally explained in this way. While the formation of habits depends upon behaviour, and much behaviour is the consequence of choice, it is not all so. Behaviour can also be impelled by instincts and through non-deliberative channels.

Another problem with Becker's argument, where habit is a possible outcome of a metapreference function, is the computational and information requirements implied by the process of learning from new experiences. ${ }^{3}$ Becker argues that every piece of information is taken into account. This implies that the brain must somehow store and retain information from all sensory inputs, at every instant of time. Clearly the amount of information involved would be enormous and increasing rapidly through time; it would quickly exceed the storage capacity of human memory.

In terms of energy requirements, the brain is very expensive. While it accounts for less than two per cent of our weight, it consumes up to twenty per cent of our calorific intake (Drubach 2000). The larger the brain, the more energy required. The evolution of the human brain was a trade-off between its survival advantages and its energy costs.

Becker's idea of a meta-preference function that accommodates all relevant information ignores these energy costs and this vital evolutionary trade-off. Despite Becker's (1976)

\footnotetext{
3 Of course, limited human computational capacity was a key issue raised by Herbert Simon (1957). Ironically, despite their overall focus on the concept of scarcity, neoclassical economists are led by their stress on rationality to overlook scarce mental capacities. For a long while, the adoption of Robbin's (1932) strictures and Friedman's (1953) 'as if' methodology diverted economists from consideration of the neural and psychological realities underpinning preferences. Fortunately, economists are now paying more attention to psychology (Rabin 1998).
} 
enduring interest in some important evolutionary themes, I have found no discussion in his work of the energy and other costs of storing and processing information in the brain. Instead, even when directly addressing the evolutionary context, Becker and his colleagues consider problems such as the solution to an 'optimal incentive problem' in terms of a 'happiness function ... based on a context-dependent reference point' that 'aggregates all information available towards assessing the individual's current performance' (Rayo and Becker 2007, p. 304).

In contrast to an imaginary brain that amasses 'all information' received, habit (in the sense of an acquired disposition) is a much cruder way of storing information from past experience. But it vastly economises on brain storage capacity. Habit crudely encapsulates past adaptive behaviour, and does not mean that every piece of information is retained.

The role of habit is illustrated by an agent-based simulation developed by Thorbjørn Knudsen and myself (Hodgson and Knudsen, 2004). The simulation considers the evolution of a traffic convention, concerning whether to drive on the left or right side of a circular track. Agents make decisions through weighted combinations of 'rational deliberation' on current information and habitual dispositions to drive on one side rather than the other. The most important result of these simulations concerns the effect of introducing processes of habituation into the modelling of agent behaviour. In most of parameter space, strength of habit can increase the systemic rate of convergence towards a left/right convention. In some circumstances it can also enhance systemic resistance to error. In short, habit helps agents to deal with uncertainty, complexity and change. But it requires relatively limited mental storage capacity.

For Becker and others, the origins of choice or rationality remain to be explained. By reversing the primacy, and installing habit as the foundation of deliberation and choice, we have the beginnings of an explanation consistent with the facts of human evolution. In turn, habit is placed on a foundation of inherited instinct, as mentioned further below.

These moves are resisted by many social scientists because of a reluctance to remove choice, reason or belief from the driving seat of human action. If habits affect behaviour then it is wrongly feared that reason and belief will be dethroned. The concern is that volition would be replaced by mechanism. However, reasons and beliefs themselves depend upon habits of thought. Habits act as necessary filters of experience and the foundations of intuition and interpretation. They are the grounding of both reflective and non-reflective behaviour. This does not make belief, reason or will any less important or real.

\section{Instincts, habits, deliberation and evolution}

From the perspective of pragmatist philosophy, Jamesian psychology and Veblenian institutional economics (Hodgson, 2004), habits are vital to all thought and behaviour. All deliberations, including rational optimisation, themselves rely on habits and rules (Hodgson 1997, Vanberg 2002, 2004). In that habits are triggered by circumstances or stimuli, they have a conditional or rule-like structure. Even rational optimisation, if and when possible, must involve rules. In turn, as suggested above, rules have to become ingrained in habits in order to be deployed by agents. Hence rational deliberation always depends on prior habits and rules as props (Hodgson, 1988). The view of Becker (1992) and others that rational choices can lead to the formation of habits is valid. But what is also being proposed here is that rational choices themselves are always and necessarily reliant on prior habits. 
Instinct is prior to habit, habit is prior to belief, and belief is prior to reason. That is the order in which they have evolved in our human ancestry over millions of years. That too is the order in which they appear in the ontogenetic development of each human individual. The capacity for belief and reason develops on a foundation of acquired instinctive and habitual dispositions. That too is the order in which they are arranged in a hierarchy of functional dependence, where the current operation of reason depends upon belief, belief depends upon habit, and habit depends upon instinct. Lower elements in the hierarchy do not entirely determine the higher functions, but they impel them into being, where they are formed in their respective natural and social context. The lower elements are necessary but not sufficient for the higher (Margolis, 1987; Murphy, 1994, Hodgson 2006b).

For Darwinian psychologists such as James, human agents possess instincts, habits and deliberative capacities. Our capacity to reason and appraise outcomes exceeds other organisms by far, but nevertheless depends upon the substrata of inherited and acquired dispositions. Darwinism embraces a 'doctrine of continuity' (Huxley, 1894, vol. 1, pp. 236-7) where consciousness and deliberation do not suddenly appear in the evolution of organisms. Hence Darwinism does not deny human intentionality but places it in an evolutionary context. Darwin $(1859$, p. 208) thus wrote in the Origin of Species: 'A little dose ... of judgement or reason often comes into play, even in animals very low in the scale of nature'. Darwin (1871, vol. 1, p. 46) restated the idea in The Descent of Man: 'animals possess some power of reasoning. Animals may constantly be seen to pause, deliberate and resolve'.

Darwinism recognizes that human reason can neither appear nor function without inherited or learned dispositional supports. Just as earlier organisms have a smidgeon of reason, human rational capacities are built on subconscious mechanisms inherited from our pre-human ancestors. We thus retain instincts and unconscious mental processes that can function independently of our conscious reasoning. As some animal species developed more complex instincts, they eventually acquired the capacity to register fortuitous and reinforced behaviours through the evolution of mechanisms of habituation. In turn, upon these mechanisms, humans built culture and language. Our layered mind, with its unconscious lower strata, maps our long evolution from less deliberative organisms. Consistent with the evolutionary doctrine of continuity, habits and instincts are highly functional evolutionary survivals of our pre-human past.

When the human species evolved its capacity to reason, it dependence on instinct and habit did not decline. Darwin (1871, vol. 1, p. 37) wrote: 'Cuvier maintained that instinct and intelligence stand in an inverse ratio to each other; and some have thought that the intellectual facilities of the higher animals have been gradually developed from their instincts. But ... no such inverse ratio really exists.' As noted below, some influential social theorists took the contrary view that intelligence and instinct preclude one another.

\section{The evolutionary survival of habits in the human species}

Both instincts and habits are important. But we need to explain why efficacious habits do not eventually get encoded in instincts after thousands of years, and further economise on the use of brain capacity. Instincts encode dispositions without the need for imitation and neural learning. We have to explain why behavioural propensities that enhance survival value are habitual rather than instinctive; we must explain why they are learned anew for each individual, rather than simply biologically inherited.

Humans have faced the problems of costly information search for hundreds of thousands of years. So we may ask: what is to stop natural selection eventually creating sophisticatedly 
programmed instincts that are sufficiently flexible to deal with most circumstances, and reduce the cost of searching for information? Cultural transmission, with its frequent mistakes of learning and imitation, is much more subject to error than the more conservative genetic inheritance system. If evolved instincts are more reliable and much less error prone, why did they not eventually provide the complete apparatus of human cognition and action?

Remarkably, Veblen addressed these issues long ago. Veblen (1914, p. 6) argued that instincts on their own were too blunt or vague as instruments to deal with the more rapidly evolving exigencies of the human condition. Habits, being more adaptable than instincts, are necessary to deal with 'the larger body of knowledge in any given community' and the 'elaborate ... ways and means interposed between these impulses and their realisation'. With intelligent organisms dealing with complex circumstances, instincts remain vital, but the modificatory power of habits becomes relatively more important. The social and natural environment is too inconstant to allow the natural selection of sufficiently complex and refined instincts to take place. Habits are acquired, additional and necessary means for instinctive proclivities to be pursued in a changing social and natural environment. As Veblen (pp. 6-7) put it:

The instinctive proclivities are essentially simple and look directly to the attainment of some concrete objective end; but in detail the ends so sought are many and diverse, and the ways and means by which they may be sought are similarly diverse and various, involving endless recourse to expedients, adaptations, and concessive adjustment between several proclivities ...

Instincts are 'essentially simple' and directed to 'some concrete objective end'. Habits are the means by which the pursuit of these ends could be adapted in particular circumstances. In comparison to instinct, habit is a relatively flexible means of adapting to complexity, disturbance and unpredictable change. Instincts are honed and selected over thousands of years and do not reflect transitory circumstances. By contrast, habits are acquired through imitation and allow much more rapid learning, often related to novel circumstances.

Veblen's line of argument suggests that humans faced diverse and changing problems in their evolution and this helped sophisticated mechanisms of habit formation to emerge. On more specific lines it could be argued that capacities for sophisticated habit formation and cultural growth emerged among humans to deal with a changing and unpredictable climatic and natural environment. Environmental change, particularly climatic change, is now emerging as a major explanation of the evolution of both intelligence and culture among humans (Potts 1996, Calvin 2002). Sophisticated human cultures first emerged in the strongly fluctuating Ice Age climates of the last few hundred thousand years.

Richerson and Robert Boyd (2001, p. 449) explain that for cultural transmission to retain its importance, environmental change must be neither too fast nor too slow: 'The largest advantage to culture comes in environments that are changing a lot on the time scale of tens of generations, but not to rapidly in any one generation.'

Accordingly, the human capacity to form habits has evolved as a result of highly variable environmental and other conditions. The next (fairly obvious) question is why the same capacity to form sophisticated and adaptable habits is not found to the same degree among other species, who endured similar environmental variations. The answer is in terms of the relatively more sophisticated development of social structures among early humanoids. Individual humans had to deal with a relatively complex social as well as natural environment. They evolved the capacity to create and sustain relatively complex social structures, but at the same time they had to evolve the capacities of communication and 
interpretation so that each individual could cope with his or her social circumstances. Habituation and sociality are linked together.

\section{Loss and reclamation in the social sciences}

In the early twentieth century, a number of social scientists followed Darwin by suggesting that reason depended on instinct and could not supplant it. The British dissident economist John Hobson (1914, p. 356) proposed 'to break down the abruptness of the contrast between reason and instinct and to recognize in reason itself the subtlest play of the creative instinct.' Similarly, the American sociologist Charles Horton Cooley (1922, p. 30) emphasized that reason 'does not supplant instinct' and 'reason itself is an instinctive disposition ... to compare, combine, and organize the activities of the mind.'

A contrary and more dismissive view of the role of instinct emerged in sociology. Émile Durkheim (1984, pp. 262, 284) wrote in 1893: 'It is indeed proven that intelligence and instinct always vary in inverse proportion to each other ... the advance of consciousness is inversely proportional to that of the instinct.' Durkheim proved much more influential for twentieth century social science than Hobson or Cooley. As the social sciences broke from biology and Darwinism in the interwar period, this false antithesis between intelligence and instinct became commonplace in twentieth century social science. ${ }^{4}$

But the breach with biology is slowly being repaired. Remarkably, with developments in modern psychology and elsewhere in the 1980s and 1990s, the views of Darwin, Veblen, Cooley and Hobson on instincts now seem remarkably modern. For instance, Howard Margolis (1987, p. 29) has pursued the hierarchy of instinct, habit and reason in the following terms:

The output of the brain ... would then consist of some blending of instinct, habit, and judgment, all subject to errors and limitations, but on the whole sufficient to make the brain capable of survival in the environment in which it operates. There is a natural hierarchy in the three modes (instinct, habit, judgment). Habits must be built out of instincts, judgment must somehow derive from instinct and habits.

The idea that that reason is in part a manifestation of instinct, and that instinct and reason are complements, has again found its time a century after James, Veblen and Cooley. Cosmides and Tooby (1994b, p. 330) wrote of 'reasoning instincts' and Henry Plotkin (1994, p. 165) has explained that:

Rationality and intelligence are extensions of instinct and can never be separated from it. The doctrine of separate determination is completely wrong. ... Instinct is the mother of intelligence.

Instinct is not the antithesis of reason, but one of its preconditions. By freeing the conscious mind from many details, instincts and habits have an essential role. If we had to deliberate upon everything, our reasoning would be paralyzed by the weight of data.

\footnotetext{
4 The tide of opinion became so strong that many who claimed to be disciples of Veblen - notably Clarence Ayres (1921a, 1921b) - eschewed the concept of instinct for the social sciences. Such views of instinct remained so influential for so long that even Hayek (1988, pp. 16-17), who increasingly adopted ideas from biology, believed that a 'gradual replacement of innate responses by learnt rules increasingly distinguished man from other animals' and typically regarded instincts as 'atavistic', 'ferocious' or 'beastly'.
} 


\section{Evolutionary versus mind-first explanations}

Much social science takes it for granted, or by definition, that 'action' is motivated exclusively by reasons based on beliefs. This proposition is undermined by modern psychology as well as the evolutionary outlook offered by Darwinism. Experiments since the 1970s show that conscious sensations are reported about half a second after neural events, and unconscious brain processes are discernable before any conscious decision to act (Libet 1985, 2004, Libet et al. 1983, Wegner 2002, 2003, Wegner and Wheatley 1999, Haynes and Rees 2005a, 2005b, Haynes et al. 2007). This evidence suggests that our dispositions are triggered before our actions are rationalized: we contrive reasons for actions already under way. ${ }^{5}$

This evidence undermines explanations of human action wholly in the terms of reasons and beliefs. However, the 'folk psychology' that beliefs are the source of intentions, choices and actions dominates social science. As critics elaborate, this ubiquitous 'folk psychology' papers over a much more complex neurophysiological reality. These 'mind-first' explanations of human behaviour are unable to explain adequately such phenomena as sleep, memory, learning, mental illness, or the effects of chemicals or drugs on our perceptions or actions. ${ }^{6}$ Mind-first conceptions erect an unsustainable dualism or discontinuity between the mental and physical worlds, which is inconsistent with the fact of human evolution.

Humans do act for reasons. But reasons and beliefs themselves are caused, and have to be explained. From a Darwinian perspective, reasoning itself is based on habits and instincts, and it cannot be sustained without them. Furthermore, consistent with the Darwinian doctrine of continuity, instincts and the capacities to form habits developed through a process of natural selection that extends way back into our pre-human past.

The adoption of a habit-based perspective implies neither stasis nor lack of choice. As Dewey (1922) explained clearly, because of our engagement with diverse and changing contexts, we develop different habits of thought and action that sometimes come into conflict with one another. Such conflicts are opportunities for choice and change. For example, government health warnings and medical advice may change our habits of thought, from regarding alcohol as enjoyable to its perception as a dangerous drug. This new habit of thought comes into conflict with our habits and addictions, and our future behaviour becomes subject to a choice. Habit does not deny choice. On the contrary, the conflicting rigidities of different habits make choice inevitable.

The biologist Ernst Mayr (1988, 1991) offers one of the clearest expositions of the importance of the Darwinian perspective for understanding human action. He fully acknowledges that human agents are purposeful, but places this in its evolutionary context. In contrast to 'teleological' notion of an evolutionary goal for the system as a whole, individual agents may be goal-driven. He uses a different word to describe individual human purposes, and gives them a specific meaning. Mayr (1988, p. 45) defines 'teleonomic' or 'programbased' behaviour as that which 'owes its goal-directedness to the operation of a program'.

\footnotetext{
5 Nevertheless, Libet (2004) argues that his experimental evidence is consistent with free will, which can intervene to block actions already foreshadowed in brain processes. Whether free will is consistent with the fact that our will is itself caused is an old philosophical controversy. To a large degree it depends on what precisely is meant by 'free will' (Dennett 1984). 6 See Bunge (1980); Stich (1983); P. M. Churchland (1984, 1989); P. S. Churchland (1986); Damasio (1994);
Rosenberg (1995, 1998); Kilpinen (2000).
} 
Such behaviour is governed by connected, rule-like dispositions, in some ways similar to a computer program. There remain enormous differences between a human mind and a computer, but they share this common, rule-driven or program-based characteristic.

Viktor Vanberg $(2002,2004)$ elaborates Mayr's argument, and shows that it provides a powerful alternative to the idea - found in both Marxism and mainstream economics - that human agency can be explained essentially in terms of rational deliberation. The assumption that human behaviour is determined by emerging rational appraisal of interests (Marx), or a given preference function (neoclassical economics), lacks an explanation of the origin or operation of these rational capacities or preferences. The technology of rationality is assumed rather than explained.

By contrast, the program-based approach relies on evolutionary theory to explain the origin of systems of rule-like dispositions, which are either inherited as instincts, or acquired as habits in a historically specific cultural setting. Generally, the human problem-solving capacity that rational choice theory attributes to 'rationality', and Marxism to informed deliberation, is explained in the Darwinian terms by the knowledge of the world that is incorporated in rules or programs that guide behaviour. This knowledge has been accumulated through trial and error in the processes of human evolution and individual learning. Knowledge, in short, consists of adaptations that have emerged in an evolutionary process (Plotkin 1994).

Towards the end of the nineteenth century, Darwinian thinking prompted a reconceptualisation of the relationship between mind and matter, which was expressed in the pragmatist philosophy of Charles Sanders Peirce, William James, John Dewey and others. Pragmatism was eclipsed by the rise of logical positivism in the 1930s and was marginalized until the 1980s. Pragmatist philosophy is now enjoying a revival (Hands 2001, p. 214). One of its leading exponents, Hans Joas (1996, p. 158), succinctly summarized the pragmatist contribution in this area:

The alternative to a teleological interpretation of action, with its inherent dependence on Cartesian dualisms, is to conceive of perception and cognition not as preceding action but rather as a phase of action by which action is directed and redirected in its situational contexts. According to this alternative view, goal-setting does not take place by an act of intellect prior to the actual action, but is instead the result of a reflection on aspirations and tendencies that are pre-reflexive and have already always been operative. In this act of reflection, we thematize aspirations which are normally at work without our being actively aware of them. But where exactly are these aspirations located? They are located in our bodies. It is the body's capabilities, habits and ways of relating to its environment which form the background to all conscious goal-setting, in other words, to our intentionality. Intentionality itself, then, consists in a self-reflective control which we exercise over our current behavior.

Pragmatism offers a means of overcoming the Cartesian dualism of body and mind, which still pervades the social sciences. Intellect is not regarded as an independent and ungrounded causal power, but as an emergent and active property of already-engaged dispositions and unfolding actions. The reality and importance of human intentionality and creativity is reconciled with the Darwinian evolutionary legacy and philosophical materialism. 


\section{Concluding remarks}

To understand the changing fortunes of the concept of habit in the social sciences we must appreciate two profound shifts in the social sciences: first the adoption of the Parsons-Robbins consensus in the 1930s, and second how that consensus has become fractured today (Camic 1986, Degler 1991, Hodgson 2004). Lionel Robbins (1932) made economics the 'science of choice', assuming individuals with given preferences. Talcott Parsons (1937) saw sociology as the science of social structures, norms and values. Neither approach made much use of psychology. When psychology did enter the picture it was almost universally the newlyestablished behaviourism of John B. Watson (1924) and others, which concentrated in positivist fashion on conditioning and overt behaviour, to the neglect of the unobservable mechanisms - innate or acquired - that lay behind appearances.

When economics and sociology abandoned instinct-habit psychology they allowed a dualist ontology of the mental and material to re-enter their disciplines. Psychology was ignored, preferences were taken as given, or the mind was taken as a blank slate, to be written upon by experience. All these stances are inconsistent with a Darwinian perspective and the fact of gradual human evolution from species with lesser deliberative capacities.

This perspective is a serious challenge for both economics and sociology. If we place human cognition in its evolutionary context, restore habit and instinct to their proper place in human decision-making, and acknowledge the empirical 'Libet Gap' between unconscious mental activity and subsequent deliberation, then the supreme totem of choice in economics must be abandoned. Furthermore, in sociology and elsewhere, any primacy of belief and deliberation is similarly challenged. Choice is real, but it is caused. ${ }^{7}$ Understanding these causes has consequences for the type mental capacities that are assumed.

Compared with economics, sociology made a much more radical break with biology in the in the interwar period, and is experiencing more difficulty than economics in accommodating evolutionary ideas. Consequently, sociology is in an even deeper theoretical crisis than economics. Its transcendence will require the critical rehabilitation of earlier traditions of sociology, including names such as Franklin Henry Giddings (1896), Lester Frank Ward (1903) and Charles Horton Cooley (1922), who engaged more closely with Darwinian ideas, in contrast to favoured classic thinkers such as Marx, Durkheim, Weber and Parsons.

Two diagrams illustrate the differences involved. Figure 1 illustrates the type of 'mind first' or 'beliefs first' model that dominates much of the social sciences.

\footnotetext{
7 By contrast, some economists see choice as an 'uncaused cause' (Shackle 1976) or uphold a view of human agency as 'free of external causes' (Minkler 2008, p. 21). For a critique of such claims of 'uncaused causes' see Hodgson (2004, pp. 61-2, 87-9).
} 




By contrast, figure 2 places human cognition in an evolutionary perspective, showing how instincts and habits underpin beliefs. In turn, in a population, cultural selection acts on habits and natural selection upon instincts. ${ }^{8}$

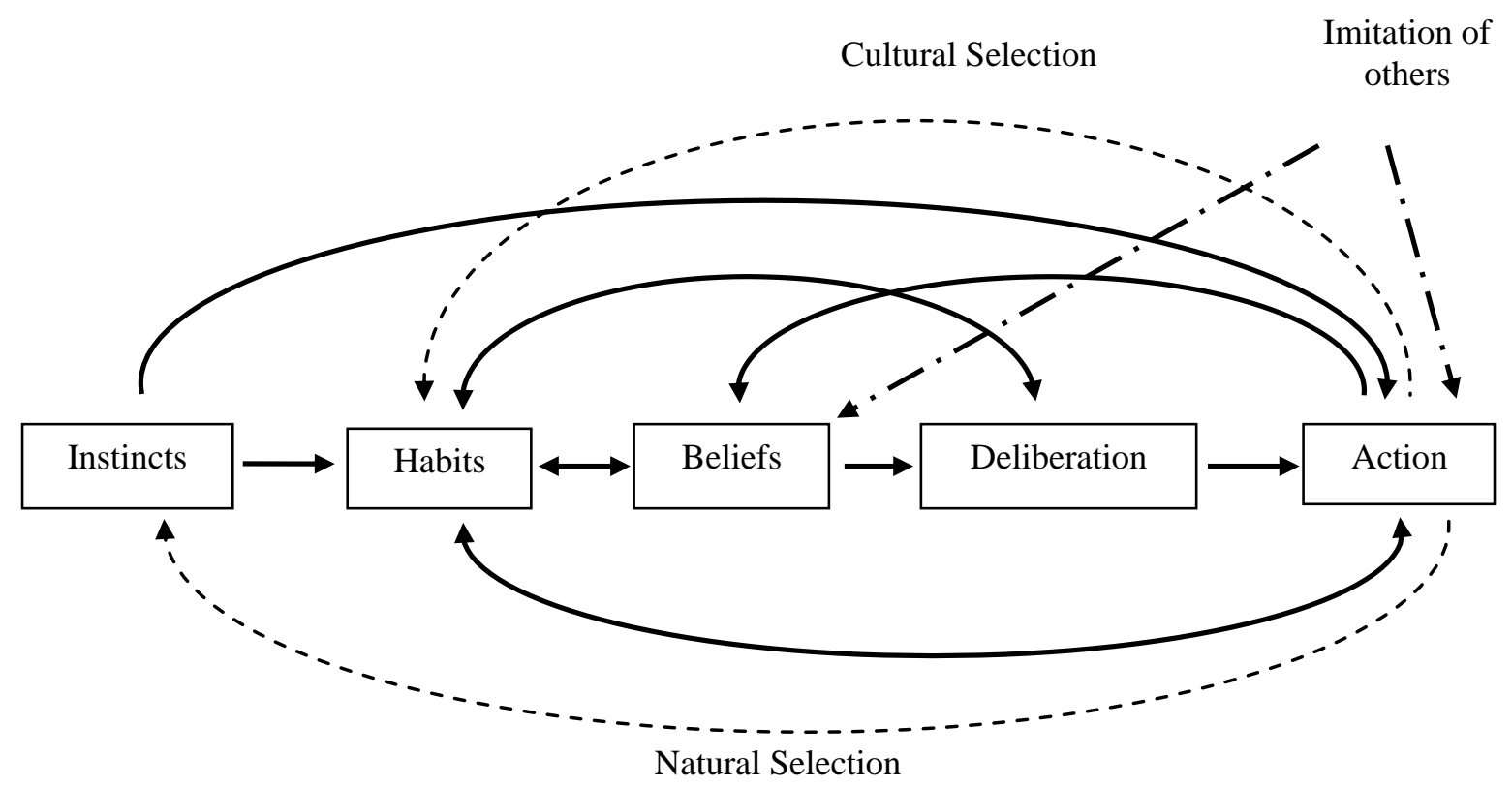

Figure 2: A Darwinian Conception of Human Cognition and Action

This discussion raises questions about the scope and boundaries of the existing disciplines in the social sciences that cannot be answered here (Hodgson 2008). Nevertheless, even if some boundaries between the disciplines are to be retained, despite their vagueness at the present time, the impact of Darwinian and evolutionary ideas cannot be ignored. It cannot simply be a question of a division of labour where the psychologists are asked to give information on individual preferences that is then plugged in as data into the economists'

\footnotetext{
8 Figure 2 neglects the important proposal by evolutionary psychologists Cosmides and Tooby (1994a, 1994b) that the brain is not an all-purpose calculator but segmented or 'modularized'. Incorporation of this insight would require significant further development and complication of the figure.
} 
models. As the discussion here of Becker's work shows, a full appreciation of the evolutionary issues overturns mainstream conceptions of choice and habit. As Kenneth Arrow (1986, p. S386) noted some time ago, a theory of habit in economic models could 'more powerful than standard theory and at least as capable of being tested.'

Once habit is seen as the foundation of preferences or beliefs, we can develop an enriched understanding of the interaction between individuals and institutions, including of the causal mechanisms involved. Emergent institutions help to pattern individual behaviour. Consequently, individuals develop and reinforce habits consistent with that behaviour, upon which revised beliefs and preferences transpire (Hodgson and Knudsen 2004). These revised beliefs or preferences lead to further actions, which may affect institutions, and so on. This gives us two-way mechanisms of reconstitutive interaction, from individuals to institutions and back to individuals (Hodgson 2006a).

The implications for social theory are profound, including a transcendence of the old debate between 'bottom up' (methodological individualist) and 'top down' (methodological collectivist) modes of explanation. In a fully-fledged evolutionary view, causal influences have to be acknowledged in both directions. In practice, despite the popularity of 'methodological individualism' as a term, all viable explanations of social phenomena involve both individuals and social structures: there is no known exception (Arrow 1994, Hodgson 2007a, 2007b). From an adequate evolutionary perspective, we have to understand how individuals are affected by social structures, as well as how structures are constituted by individuals. Habit is a crucial mechanism in the former case.

Some defend the view that economists take preferences as given by suggesting a division of labour between economics and psychology. Others simply claim that the assumption is the mark of economics as a discipline. Although the simplifying assumptions of given preferences is legitimate in some cases, it should not be obligatory within economics in all circumstances (Knight 1924). Since the 1990s this view has returned to economics. Not only is psychology being widely embraced by economists (Rabin 1998), but several leading economists consider the endogeneity of preferences as a legitimate topic within the discipline (Bowles 1998, 2004, North 1994, Akerlof and Kranton 2005). Much work within evolutionary economics has already moved in the same direction. 


\section{References}

Akerlof, George A. and Kranton, Rachel E. (2005) 'Identity and the Economics of Organizations', Journal of Economic Perspectives, 19(1), Winter, pp. 9-32.

Arrow, Kenneth J. (1986) 'Rationality of Self and Others in an Economic System', Journal of Business, 59(4.2), October, pp. S385-S399.

Arrow, Kenneth J. (1994) 'Methodological Individualism and Social Knowledge', American Economic Review (Papers and Proceedings), 84(2), May, pp. 1-9.

Ayres, Clarence E. (1921a) 'Instinct and Capacity - I: The Instinct of Belief-in-Instincts', Journal of Philosophy, 18, No. 21, October 13, pp. 561-5.

Ayres, Clarence E. (1921b) 'Instinct and Capacity - II: Homo Domesticus', Journal of Philosophy, 18, No. 22, October 27, pp. 600-6.

Becker, Gary S. (1962) 'Irrational Behavior and Economic Theory', Journal of Political Economy, 70(1), February, pp. 1-13.

Becker, Gary S. (1976) 'Altruism, Egoism, and Genetic Fitness: Economics and Sociobiology', Journal of Economic Literature, 14(2), December, pp. 817-26.

Becker, Gary S. (1992) 'Habits, Addictions and Traditions', Kyklos, 45, Fasc. 3, pp. 327-46.

Becker, Gary S. and Murphy, Kevin M. (1988) ‘A Theory of Rational Addiction', Journal of Political Economy, 96(4), pp. 675-700.

Bowles, Samuel (1998) 'Endogenous Preferences: The Cultural Consequences of Markets and Other Economic Institutions', Journal of Economic Literature, 36(1), March, pp. 75-111.

Bowles, Samuel (2004) Microeconomics: Behavior, Institutions, and Evolution (Princeton, NJ and New York: Princeton University Press and Russell Sage Foundation).

Bunge, Mario A. (1980) The Mind-Body Problem: A Psychobiological Approach (Oxford: Pergamon).

Calvin, William H. (2002) A Brain for All Seasons: Human Evolution and Abrupt Climate Change (Chicago: University of Chicago Press).

Camic, Charles (1986) 'The Matter of Habit', American Journal of Sociology, 91(5), March, pp. 1039-87.

Churchland, Patricia S. (1986) Neurophilosophy: Toward a Unified Science of the Mind-Brain (Cambridge, MA: MIT Press).

Churchland, Paul M. (1984) Matter and Consciousness (Cambridge, MA: MIT Press).

Churchland, Paul M. (1989) A Neurocomputational Perspective: The Nature of Mind and the Structure of Science (Cambridge, MA: MIT Press).

Chomsky, Noam (1959) 'Review of Verbal Behavior by B. F. Skinner', Language, 35, pp. 2658.

Cooley, Charles Horton (1922) Human Nature and the Social Order, $2^{\text {nd }}$ edn. (New York: Scribner's).

Cosmides, Leda and Tooby, John (1994a) 'Beyond Intuition and Instinct Blindness: Towards an Evolutionary Rigorous Cognitive Science’, Cognition, 50(1-3), April-June, pp. 41-77. 
Cosmides, Leda and Tooby, John (1994b) 'Better than Rational: Evolutionary Psychology and the Invisible Hand', American Economic Review (Papers and Proceedings), 84(2), May, pp. 327-32.

Damasio, Antonio R. (1994) Descartes' Error: Emotion, Reason, and the Human Brain (New York: Putnam).

Darwin, Charles R. (1859) On the Origin of Species by Means of Natural Selection, or the Preservation of Favoured Races in the Struggle for Life, $1^{\text {st }}$ edn. (London: Murray).

Darwin, Charles R. (1871) The Descent of Man, and Selection in Relation to Sex, $1^{\text {st }}$ edn., 2 vols (London: Murray and New York: Hill).

Darwin, Charles R. (1974) Metaphysics, Materialism, and the Evolution of Mind: Early Writings of Charles Darwin, transcribed and annotated by Paul H. Barrett with a commentary by Howard E. Gruber (Chicago: University of Chicago Press).

Degler, Carl N. (1991) In Search of Human Nature: The Decline and Revival of Darwinism in American Social Thought (Oxford and New York: Oxford University Press).

Dennett, Daniel C. (1984) Elbow Room: The Varieties of Free Will Worth Wanting (Cambridge, MA: MIT Press).

Dewey, John (1894) 'The Ego as Cause', The Philosophical Review, 3(3), May, pp. 337-41.

Dewey, John (1922) Human Nature and Conduct: An Introduction to Social Psychology, 1st edn. (New York: Holt).

Drubach, Daniel (2000) The Brain Explained (Englewood Cliffs, NJ: Prentice-Hall).

Durkheim, Émile (1984) The Division of Labour in Society, translated from the French edition of 1893 by W. D. Halls with an introduction by Lewis Coser (London: Macmillan).

Friedman, Milton (1953) 'The Methodology of Positive Economics', in M. Friedman, Essays in Positive Economics (Chicago: University of Chicago Press), pp. 3-43.

Giddings, Franklin Henry (1896) The Principles of Sociology: An Analysis of the Phenomena of Association and of Social Organization (New York: Macmillan).

Hands, D. Wade (2001) Reflection Without Rules: Economic Methodology and Contemporary Science Theory (Cambridge and New York: Cambridge University Press).

Hayek, Friedrich A. (1988) The Fatal Conceit: The Errors of Socialism. The Collected Works of Friedrich August Hayek, Vol. I, ed. William W. Bartley III (London: Routledge).

Haynes, John-Dylan and Rees, Geraint (2005) 'Predicting the Orientation of Invisible Stimuli from Activity in Human Primary Visual Cortex', Nature Neuroscience, 8(5), May, pp. 686-91.

Haynes, John-Dylan and Rees, Geraint (2005) 'Predicting the Stream of Consciousness from Activity in Human Visual Cortex’, Current Biology, 15(14), pp. 1301-7.

Haynes, John-Dylan, K. Sakai, G. Rees, S. Gilbert, C. Frith, R. Passingham (2007) 'Reading Hidden Intentions in the Human Brain', Current Biology, 17(4), pp. 323-8.

Hobson, John A. (1914) Work and Wealth: A Human Valuation (London: Macmillan).

Hodgson, Geoffrey M. (1988) Economics and Institutions: A Manifesto for a Modern Institutional Economics (Cambridge and Philadelphia: Polity Press and University of Pennsylvania Press). 
Hodgson, Geoffrey M. (1997) 'The Ubiquity of Habits and Rules', Cambridge Journal of Economics, 21(6), November, pp. 663-84.

Hodgson, Geoffrey M. (2004) The Evolution of Institutional Economics: Agency, Structure and Darwinism in American Institutionalism (London and New York: Routledge).

Hodgson, Geoffrey M. (2006a) Economics in the Shadows of Darwin and Marx: Essays on Institutional and Evolutionary Themes (Cheltenham: Edward Elgar).

Hodgson, Geoffrey M. (2006b) 'Instinct and Habit before Reason: Comparing the Views of John Dewey, Friedrich Hayek and Thorstein Veblen', in Advances in Austrian Economics, 9, pp. 109-43.

Hodgson, Geoffrey M. (2007a) 'Institutions and Individuals: Interaction and Evolution', Organization Studies, 28(1), January 2007, pp. 95-116.

Hodgson, Geoffrey M. (2007b) 'Meanings of Methodological Individualism', Journal of Economic Methodology 14(2), June, pp. 211-26.

Hodgson, Geoffrey M. (2008) 'Prospects for Economic Sociology', Philosophy of the Social Sciences, 38(1), March, pp. 133-49.

Hodgson, Geoffrey M. and Knudsen, Thorbjørn (2004) 'The Complex Evolution of a Simple Traffic Convention: The Functions and Implications of Habit', Journal of Economic Behavior and Organization, 54(1), pp. 19-47.

Huxley, Thomas Henry (1894) Collected Essays, 9 vols (London: Macmillan).

James, William (1893) The Principles of Psychology, $2^{\text {nd }}$ edn. (New York: Holt).

Joas, Hans (1996) The Creativity of Action, translated from the German edition of 1992 (Chicago: University of Chicago Press).

Kilpinen, Erkki (2000) The Enormous Fly-Wheel of Society: Pragmatism's Habitual Conception of Action and Social Theory (Helsinki: University of Helsinki).

Knight, Frank H. (1924) 'The Limitations of Scientific Method in Economics', in Tugwell, Rexford G. (ed.) (1924) The Trend of Economics (New York: Alfred Knopf), pp. 229-67.

Libet, Benjamin (1985) 'Unconscious Cerebral Initiative and the Role of Conscious Will in Voluntary Action', Behavioral and Brain Sciences, 8, pp. 529-66.

Libet, Benjamin (2004) Mind Time: The Temporal Factor in Consciousness (Cambridge, MA: Harvard University Press).

Libet, Benjamin, Gleason, Curtis A., Wright, Elwood W., and Pearl, Dennis K. (1983) 'Time of Conscious Intention to act in Relation to Onset of Cerebral Activity (ReadinessPotential): The Unconscious Initiation of a Freely Voluntary Act', Brain, 106(3), pp. 623642.

Margolis, Howard (1987) Patterns, Thinking and Cognition: A Theory of Judgment (Chicago: University of Chicago Press).

Mayr, Ernst (1988) Toward a New Philosophy of Biology: Observations of an Evolutionist (Cambridge, MA and London: Harvard University Press).

Mayr, Ernst (1991) One Long Argument: Charles Darwin and the Genesis of Modern Evolutionary Thought (Cambridge, MA and London: Harvard University Press and Allen Lane). 
Minkler, Lanse P. (2008) Integrity and Agreement: Economics When Principles Also Matter (Ann Arbor, MI: University of Michigan Press).

Murphy, James Bernard (1994) 'The Kinds of Order in Society', in Mirowski, Philip (ed.) (1994) Natural Images in Economic Thought: "Markets Read in Tooth and Claw" (Cambridge and New York: Cambridge University Press), pp. 536-82.

North, Douglass C. (1994) 'Economic Performance Through Time', American Economic Review, 84(3), June, pp. 359-67.

Ouellette, Judith A. and Wood, Wendy (1998) 'Habit and Intention in Everyday Life: The Multiple Processes by which Past Behavior Predicts Future Behavior', Psychological Bulletin, 124, pp. 54-74.

Parsons, Talcott (1937) The Structure of Social Action, 2 vols (New York: McGraw-Hill).

Pinker, Steven (1994) The Language Instinct: The New Science of Language and Mind (London and New York: Allen Lane and Morrow).

Plotkin, Henry C. (1994) Darwin Machines and the Nature of Knowledge: Concerning Adaptations, Instinct and the Evolution of Intelligence (Harmondsworth: Penguin).

Poldrack, Russell A., Clark, J., Pare-Blagoev, J., Shohamy, D., Creso Moyano, J., Myers, C. and Gluck, M. A. (2001) 'Interactive Memory Systems in the Human Brain', Nature, 414, 29 November, pp. 546-550.

Potts, Richard (1996) Humanity's Descent: The Consequences of Ecological Instability (New York: William Morrow).

Rabin, Matthew (1998) 'Psychology and Economics', Journal of Economic Literature, 36(1), March, pp. 11-46.

Rayo, Luis and Becker, Gary S. (2007) 'Evolutionary Efficiency and Happiness', Journal of Political Economy, 115(2), April, pp. 302-37.

Richerson, Peter J. and Boyd, Robert (2001) 'Built For Speed, Not for Comfort: Darwinian Theory and Human Culture', History and Philosophy of the Life Sciences, 23(3/4), pp. 423-63.

Robbins, Lionel (1932) An Essay on the Nature and Significance of Economic Science (London: Macmillan).

Robertson, Ian (1978) Sociology: An Introduction (New York: Worth).

Rosenberg, Alexander (1995) The Philosophy of Social Science, $2^{\text {nd }}$ edn. (Boulder, CO: Westview Press).

Rosenberg, Alexander (1998) 'Folk Psychology', in Davis, John B., Hands, D. Wade and Mäki, Uskali (eds) (1998) Handbook of Economic Methodology (Cheltenham: Edward Elgar), pp. 195-7.

Shackle, George L. S. (1976) 'Time and Choice', Proceedings of the British Academy, 66, pp. 309-29.

Simon, Herbert A. (1957) Models of Man: Social and Rational. Mathematical Essays on Rational Human Behavior in a Social Setting (New York: Wiley).

Stich, Stephen P. (1983) From Folk Psychology to Cognitive Science (Cambridge, MA: MIT Press). 
Vanberg, Viktor J. (2002) 'Rational Choice versus Program-Based Behavior: Alternative Theoretical Approaches and Their Relevance for the Study of Institutions', Rationality and Society, 14(1), Summer, pp. 7-53.

Vanberg, Viktor J. (2004) 'The Rationality Postulate in Economics: Its Ambiguity, Its Deficiency and Its Evolutionary Alternative', Journal of Economic Methodology, 11(1), March, pp. 1-29.

Veblen, Thorstein B. (1898) 'Why Is Economics Not an Evolutionary Science?' Quarterly Journal of Economics, 12(3), July, pp. 373-97.

Veblen, Thorstein B. (1914) The Instinct of Workmanship, and the State of the Industrial Arts (New York: Macmillan).

Ward, Lester Frank (1903) Pure Sociology: A Treatise on the Origin and Spontaneous Development of Society (New York and London: Macmillan).

Watson, John B. (1924) Behaviorism (New York: W. W. Norton).

Wegner, Daniel M. (2002) The Illusion of Conscious Will (Cambridge, MA: MIT Press).

Wegner, Daniel M. (2003) 'The Mind's Best Trick: How We Experience Conscious Will', Trends in Cognitive Sciences, 7(2), February, pp. 65-69.

Wegner, Daniel M. and Wheatley, T. (1999) 'Apparent Mental Causation: Sources of the Experience of the Will', American Psychologist, 54, pp. 480-92.

Wood, Wendy and Neal, David T. (2007) 'A New Look at Habits and the Habit-Goal Interface', Psychological Review, 114(4), October, pp. 843-863.

Wood, Wendy, Quinn, Jeffrey M. and Kashy, D. (2002) 'Habits in Everyday Life: Thought, Emotion, and Action', Journal of Personality and Social Psychology, 83, pp. 1281-97. 